\title{
Thermal and Exergy Assessment of a Micro Combustor Fueled by Premixed Hydrogen/Air under Different Sizes: a Numerical Simulation
}

\author{
E. Nadimi ${ }^{\dagger}$ and S. Jafarmadar \\ Department of Mechanical Engineering, School of Engineering, Urmia University, Urmia, West Azerbaijan, \\ Iran \\ †Corresponding Author Email: st_e.nadimi@urmia.ac.ir
}

(Received October 18, 2019; accepted Decmber 31, 2019)

\begin{abstract}
In this work, a numerical study has been carried out in order to investigate the effects of a micro combustor size on the exergy and energy efficiencies of a premixed hydrogen/air for a micro thermophotovoltaic system. For this purpose, six combustors in different sizes are designed, in which geometry dimensional size gradually reduced. The effects of the combustor size on the entropy, exergy, radiation power, and energy conversion efficiency are investigated. Also, mean and uniform wall temperature are discussed. In order to compare the entropy generation of each micro combustor, a dimensionless entropy generation rate is defined. The hydrogen/air combustion with 9 species and 19 reversible elementary reactions were simulated by using the Eddy Dissipation Concept (EDC) model. Results indicate the micro-combustor geometry size has important effects. A reduction of the combustor geometry size dimensionality causes an increase in average wall temperature and makes it uniform. Moreover, by decreasing micro combustor size, the radiation power efficiency increases from 41.96 to $45.62 \%$ and total energy conversion efficiency from 6.46 to $7.02 \%$. The highest exergy efficiency, $38.63 \%$, is achieved in the smallest micro combustor while the minimum exergy efficiency $33.22 \%$, is obtained in the largest micro combustor.
\end{abstract}

Keywords: Micro combustor size; Wall temperature; Entropy generation; Exergy efficiency; Thermal performance.

\section{NOMENCLATURE}

$\begin{array}{llll}A_{i} & \text { The surface area of element } i \text { on the } & L_{1} & \text { Micro combustor length } \\ & \text { external wall } & L_{2} & \text { Micro combustor step length } \\ C_{P_{\text {outlet }}} & \text { Specific heat capacity of the exhaust } & \dot{m} & \text { Inlet mass flow rate } \\ & \text { gases } & \dot{m}_{H_{2}} & \text { Hydrogen mass flow rate } \\ D_{1} & \text { The inlet diameter } & n_{j} & \text { The number density of species j } \\ D_{2} & \text { The outlet diameter } & P_{0} & \text { Ambient pressure } \\ D_{3} & \text { The outer diameter of the micro } & \dot{Q}_{R} & \text { Chemical heat release rate } \\ & \text { combustor } & \dot{Q}_{R a d} & \text { Radiation heat transfer } \\ \dot{E}_{\text {loss }} & \text { The energy loss } & \dot{Q}_{w a l l} & \text { Heat transfer from the external wall } \\ E_{T} & \text { Total fluid energy } & R_{\text {outlet }} & \text { Specific gas constant at the outlet } \\ \dot{E}_{\text {loss }} & \text { Exergy loss } & R_{u} & \text { Ideal gas constant } \\ h_{0} & \text { Free convection heat transfer coefficient } & R_{T} & \text { Nonuniformity coefficient } \\ h_{j} & \text { Enthalpy of each species } & S_{\mathrm{f}} & \text { Enthalpy source } \\ \mathrm{I} & \text { Unit tensor } & s & \text { Specific entropy } \\ \vec{J}_{j} & \text { Diffusion flux of species j } & \dot{\mathrm{S}}_{\mathrm{gen}} & \text { Total entropy generation rate } \\ k_{f} & \text { Fluid conductivity } & \end{array}$


E. Nadimi and S. Jafarmadar / JAFM, Vol. 13, No. 4, pp. 1233-1243, 2020.

$\begin{array}{ll}T_{i} & \text { The temperature of element } i \\ T_{m} & \text { Mean wall temperature } \\ T_{\text {outlet }} & \text { Outlet Temperature } \\ \vec{u} & \text { Velocity vector } \\ u & \text { Specific internal energy } \\ \overline{\mathrm{W}} & \text { Average molecular weight } \\ Y_{j} & \text { Mass fraction of each species } \\ \rho & \\ \mu & \text { Density } \\ \mu_{j} & \text { Molecular viscosity } \\ & \text { Chemical potential of each species }\end{array}$

\section{INTRODUCTION}

Today, small-scale devices are being developed, with the appearance of science and technology, and need to construct small-scale devices. Energy sources for these devices are batteries, micro gas turbines, micro thermophotovoltaic systems. Batteries have limitations such as a low energy density, long recharging time, relatively short lifetime, heavyweight. The Micro Thermophotovoltaic (MTPV) power generator is one of the best choices for power generation because it has not included any moving parts, easy to manufacture, and high energy density ( $\mathrm{Su}$ et al. (2015)). The MTPV systems include three basic parts, which are a combustion chamber, a PV cell array, and an emitter (Yang et al. (2002)). To illustrate the function of the MTPV systems, chemical energy during a combustion process of hydrogen and air causes rising the wall temperature of a micro combustor and thermal radiation flux released from the combustor wall. It is absorbed by the PV cell array, and then electric power is generated.

A lot of researches have been done to improve radiation heat transfer, energy efficiency, flame stability, uniform wall temperature, and structure optimization for a micro combustor of the MTPV system. Yang et al. (2007) experimentally studied micro cylindrical combustor with a backwardfacing step and the combustor diameter. They show that raising the height of the backward-facing step of the micro combustor and reducing the combustor diameter can improve the short circuit current total energy conversation of the MTPV device. Wan et al. (2012) investigated experimentally and numerically lean hydrogen-air combustion in a planar micro combustor with a bluff body and found that increasing the equivalence ratio from 0.4 to 0.6 causes an increase in the blow-off limit range. Moreover, with increasing inlet velocity, the flame is long and becomes thin, and the high-temperature zone of wall shifts downstream. A uniform and high wall temperature distribution on the micro combustor is effective to receive higher energy efficiency. Gradually reducing the wall thickness of the micro-cylindrical combustor makes wall

$\begin{array}{ll}\omega_{j} & \text { Reaction rate } \\ \eta_{\mathrm{II}} & \text { Exergy efficiency } \\ \sigma & \text { Boltzmann constant } \\ \varepsilon & \text { Surface emissivity }\end{array}$

$\begin{array}{ll}\text { Abbreviations } \\ \text { con } & \text { Conversion } \\ \text { gen } & \text { Generation } \\ \text { in } & \text { Inlet } \\ \text { LHV } & \text { Low heat value } \\ \text { rad } & \text { Radiation } \\ \text { sur } & \text { Surrounding } \\ \text { TPV } & \text { Thermophotovoltaic }\end{array}$

temperature distribution higher and more uniform, which is proposed by Zuo et al. (2017). Akhtar et al. (2015) showed the effects of channel crosssection (circular, rectangular, square, trapezoidal, and triangular) on the total efficiency. Also, they reported that a Reynolds Stress Model (RSM) for turbulent flow with the Eddy Dissipation Concept (EDC) model for combustion proses, gives the best prediction of the wall temperature. Su et al. (2015) found that the usage of a two-cavity and one-cavity for the micro combustor caused that radiation power is increased from $2.1 \mathrm{~W}$ for one cavity to $2.5 \mathrm{~W}$ for two cavities. The irreversible energy loss and entropy generation in combustion proses cannot be neglected. The entropy generation in the microcombustion process has been carried out by some researchers (Peng et al. (2018); Huang et al. (2019)). In recent years, exergy analysis has been used for the micro combustor. Jiaqiang et al. (2016) investigated the effect of inlet pressure on entropy generation and temperature distribution in premixed hydrogen-air combustion in a circular microcombustor. Their results suggested that when inlet pressure is $\mathrm{P}=100 \mathrm{KPa}$, the maximum exergy efficiency is reached 40 percent. The minimum exergy efficiency is obtained 36 percent when the inlet pressure is $\mathrm{P}=60 \mathrm{KPa}$. Moreover, they reported that the maximum average wall temperature is achieved at $\mathrm{P}=0 \mathrm{KPa}$ while the highest wall temperature difference is reported at $\mathrm{P}$ $=100 \mathrm{KPa}$. Also, the maximum energy efficiency is obtained at $\mathrm{P}=20 \mathrm{KPa}$. The bluff body was used to improve uniform wall temperature and micro combustor performance. Jiang et al. (2014) numerically studied the entropy generation distribution in the hydrogen-air mixer in the micro combustor. Their numerical results showed that the stoichiometric mixture has maximum entropy generation but minimum entropy generation is obtained in a rich and lean premixed hydrogen-air. $\mathrm{Ni}$ et al. (2019) numerically studied a micro combustor with the rib, they observed that the micro combustor with two ribs works more efficiently than one rib. they reported that the chemical reaction contributed about 70 percent of the total entropy generation.

Many types of research have been done on micro 


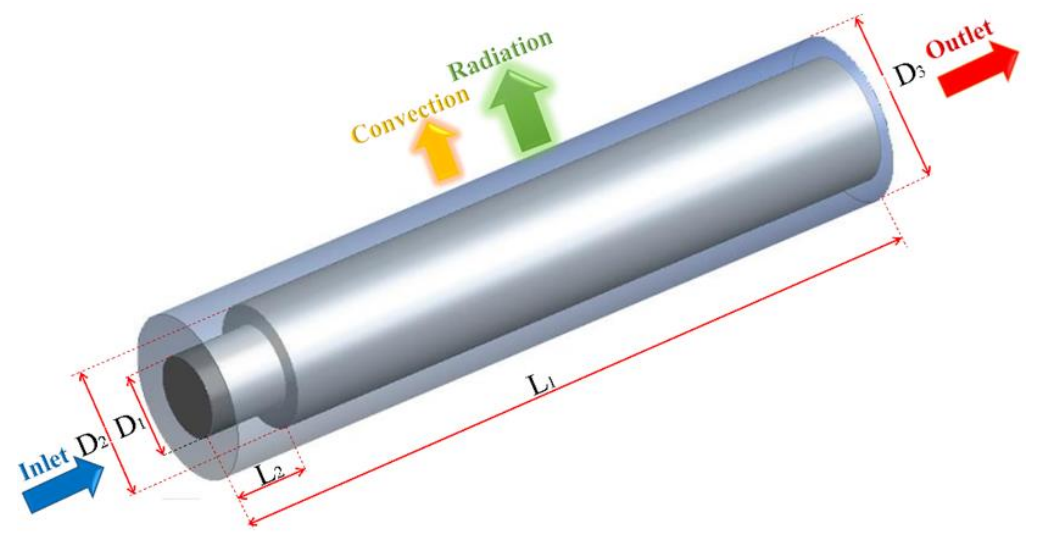

Fig. 1. Schematic of the micro-combustor.

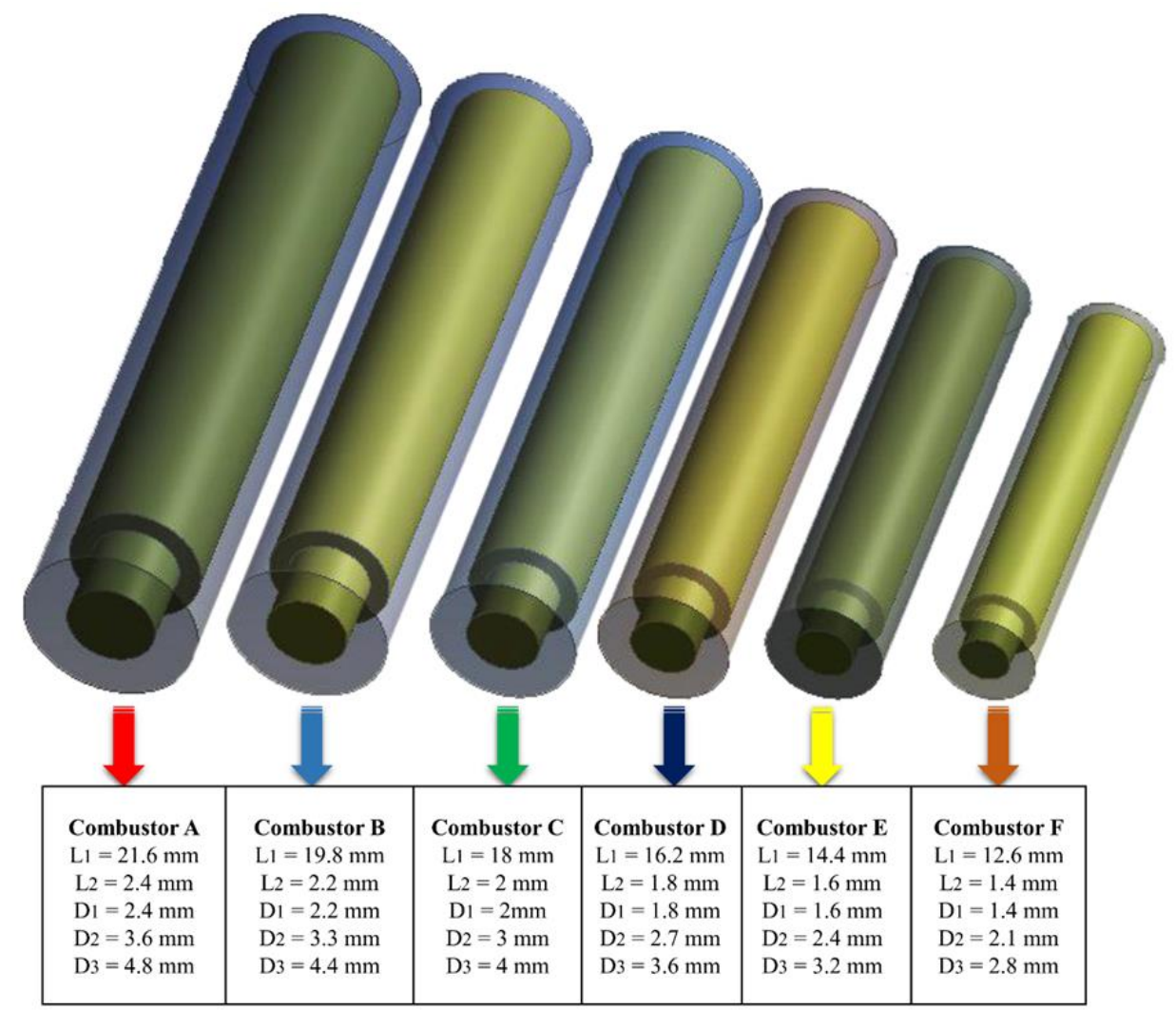

Fig. 2. Geometry and dimensions of the micro combustors.

combustor, but most of them have been studied to achieve uniform wall temperature and to increase the energy performance and electric power production of the MTPV systems. No research has so far been carried out to study the effect of the micro-combustor size on the entropy generation distribution, total energy efficiency, and exergy efficiency. In this work, a three-dimensional simulation and numerical investigation of the effects of the micro-combustor scale on the entropy generation, exergy efficiency and wall temperature have been done under the same boundary conditions where inlet velocity is $5 \mathrm{~m} / \mathrm{s}$, and the premixed
$\mathrm{H}_{2}$ /air equivalence is 1 .

\section{DESCRIPTION OF THE NUMERICAL MODEL}

\subsection{Micro Combustor Geometry}

The micro-combustor geometry is shown in Fig. 1. The total length $\left(L_{1}\right)$; step length $\left(L_{2}\right)$; inlet diameter $\left(D_{1}\right)$; outlet diameter $\left(D_{2}\right)$, and the outer diameter $\left(D_{3}\right)$ are the dimensions of the micro-combustors. The micro combustors are made of 316 stainless steel, which its physical properties presented in 
Table 1 (Wan et al. (2015)). We used six micro combustors (A, B, C, D, E, F) in different scales for CFD simulation. Its sizes can be seen in Fig. 2.

Table 1 Properties of stainless steel

\begin{tabular}{|c|c|c|c|}
\hline Properties & Density & $\begin{array}{c}\text { Thermal } \\
\text { conductivity }\end{array}$ & $\begin{array}{c}\text { Specific } \\
\text { heat }\end{array}$ \\
\hline $\begin{array}{c}\text { stainless } \\
\text { steel }\end{array}$ & 8000 & 12.0 & 503 \\
\hline
\end{tabular}

\subsection{Mathematical Model}

Before building the pursuant governing equations, some assumptions are essential for simplifying the mathematical model as follows: (a) combustion process is a steady-state; (b) The $\mathrm{H}_{2} /$ air premixed is uniform; (c) No Dufour effect (Williams (1965)); (d) The work done by pressure forces and viscous are ignored; (e) No gas radiation in the combustion channel but the radiation between the out wall and the environment are considered (Norton et al. (2004)); (f) No surface reactions.

The governing equations are then given as follows:

Continuity and momentum conservation equation:

$\nabla \cdot(\rho \vec{u})=0$

$\rho(\vec{u} \cdot \nabla \vec{u})=-\nabla P+\nabla \cdot\left(\left(\mu+\mu_{T}\right)\left[\nabla \vec{u}+(\nabla \vec{u})^{T}-\frac{2}{3} \nabla \cdot \vec{u} I\right]\right)$

Where $\rho$ and $\vec{u}$ are the fluid density and the velocity vector. And $P$ is the pressure, $\mu_{T}$ is the turbulent viscosity, and $I$ is the unit tensor.

Energy conservation equation:

$$
\begin{aligned}
& \nabla \cdot \vec{u}\left(\rho E_{T}+P\right)=\nabla \cdot\left[\left(k_{f}+\frac{C_{P} \mu_{T}}{\operatorname{Pr}_{T}}\right) \nabla T-\left(\sum_{j} h_{j} \vec{J}_{j}\right)\right] \\
& +\nabla \cdot\left[\left(\mu+\mu_{T}\right)\left(\nabla \vec{u}+(\nabla \vec{u})^{T}-\frac{2}{3} \nabla \cdot \vec{u} I\right)\right] \cdot \vec{u}+S_{f}
\end{aligned}
$$

Where $E_{T}$ is total fluid energy, $k_{f}$ is the fluid conductivity, $\operatorname{Pr}_{T}$ is the turbulent Prandtl number, $\vec{J}_{j}$ is the diffusion flux of species $j, h_{j}$ is the enthalpy of species $j$, and $S_{f}$ is the fluid enthalpy source.

Energy equation for the solid zone:

$\nabla \cdot\left(K_{s} \cdot \nabla T\right)=0$

Where $K_{s}$ denotes the solid domain thermal conductivity

Ideal gas equation (Alipoor et al. (2017)):

$P=\rho \frac{R_{u}}{\overline{\mathrm{W}}} T$

Where $\overline{\mathrm{W}}$ and $R_{u}$ are the average of molecular weight of the $\mathrm{H}_{2} /$ air mixture and the ideal gas constant.

Species transport equations:

$\nabla \cdot\left(\rho \vec{u} Y_{j}\right)=\nabla \vec{J}_{j}+\omega_{j}$

Where $\omega_{j}$ is the net production rate of species $\mathrm{j}$.

Entropy transport equation:

$T d s=d u+P d\left(\frac{1}{\rho}\right)-\sum_{j=1}^{n} \mu_{j} d\left(\frac{n_{j}}{\rho}\right)$

$\dot{\mathrm{S}}_{\mathrm{gen}}=\dot{m}\left(s_{\text {outlet }}-s_{\text {in }}\right)$

Where $\dot{\mathrm{S}}_{\text {gen }}$ is the total entropy generation rate, $s$ is the specific entropy, $\dot{\mathrm{m}}$ is the mass flow rate, $u$ and $\mu_{j}$ are the internal energy and the chemical potential of each species, and $n_{j}$ is the number density of species $j$.

Under the second law of thermodynamics, exergy loss, and the exergy efficiency (Sahoo et al. (2012)) are defining as below:

$\dot{E} x_{i n}=\dot{m}_{H_{2}} \times Q_{L H V}$

$\dot{E} x_{\text {loss }}=\dot{E}_{\text {loss }}+\left[\dot{m} \times T_{\text {sur }} \times\left(C_{P_{\text {oulte }}} \ln \frac{T_{\text {sur }}}{T_{\text {outlet }}}-R_{\text {outlet }} \ln \frac{P_{0}}{P_{\text {outlet }}}\right)\right]$

$\eta_{\mathrm{II}}=\frac{\dot{E} x_{i n}-\dot{E} x_{\text {loss }}}{\dot{E} x_{i n}}$

Where $\dot{E}_{\text {loss }}$ is the energy loss by the outlet gases, $Q_{L H V}$ is hydrogen lower heating value that is assumed to be $119 \mathrm{MJ} / \mathrm{kg}$ (Turns (2002)).

The total heat transfer $\left(\dot{Q}_{\text {wall }}\right) \square$ between the external wall of the micro combustor and the environment is defined as follows:

$$
\begin{aligned}
& \dot{Q}_{\text {wall }}=\dot{Q}_{\text {Rad }}+\dot{Q}_{\text {con }} \\
& \dot{Q}_{\text {Rad }}=\varepsilon \sigma \sum_{i=1}^{n} A_{i}\left(T_{i}^{4}-T_{\text {sur }}^{4}\right) \\
& \dot{Q}_{\text {Con }}=h_{0}\left(T_{i}-T_{\text {sur }}\right)
\end{aligned}
$$

Where $\sigma, \varepsilon$ are Boltzmann constant and surface emissivity, respectively. $T_{i}, A_{i}$ are the temperature and the surface area of element $i$ at the outer wall and $h_{0}$ is the heat transfer coefficient.

The radiation power efficiency $\left(\eta_{\mathrm{Rad}}\right)$ is defined as the ratio of the radiation heat transfer rate $\left(\dot{Q}_{\text {Rad }}\right)$ from the outer wall of the micro-combustor to the heat of reaction $\left(\dot{Q}_{R}\right)$ :

$\eta_{\text {Rad }}=\frac{\dot{Q}_{R a d}}{\dot{Q}_{R}}$

The total energy conversion efficiency in the micro 
E. Nadimi and S. Jafarmadar / JAFM, Vol. 13, No. 4, pp. 1233-1243, 2020.

Table $2 \mathrm{H}_{2} /$ air chemical reaction mechanism

\begin{tabular}{|c|c|c|c|}
\hline Reaction & $\begin{array}{c}\mathrm{A} \\
\left(\mathrm{m}^{3} / \mathrm{kmol} \mathrm{s}\right)\end{array}$ & $\beta$ & $\mathrm{E}(\mathrm{J} / \mathrm{kmol})$ \\
\hline $\mathrm{H}+\mathrm{O}_{2}=\mathrm{O}+\mathrm{OH}$ & $5.1 \times 10^{13}$ & -0.82 & $6.91 \times 10^{7}$ \\
\hline $\mathrm{H}_{2}+\mathrm{O}=\mathrm{H}+\mathrm{OH}$ & $1.8 \times 10^{7}$ & 1.0 & $3.7 \times 10^{7}$ \\
\hline $\mathrm{H}_{2}+\mathrm{OH}=\mathrm{H}_{2} \mathrm{O}+\mathrm{H}$ & $1.2 \times 10^{7}$ & 1.3 & $1.52 \times 10^{7}$ \\
\hline $\mathrm{OH}+\mathrm{OH}=\mathrm{H}_{2} \mathrm{O}+\mathrm{O}$ & $6.0 \times 10^{6}$ & 1.3 & 0.0 \\
\hline $\mathrm{H}+\mathrm{OH}+\mathrm{M}=\mathrm{H}_{2} \mathrm{O}+\mathrm{M}^{\mathrm{a}}$ & $7.5 \times 10^{17}$ & -2.6 & 0.0 \\
\hline $\mathrm{O}_{2}+\mathrm{M}=\mathrm{O}+\mathrm{O}+\mathrm{M}$ & $1.9 \times 10^{8}$ & 0.5 & $4.001 \times 10^{8}$ \\
\hline $\mathrm{H}_{2}+\mathrm{M}=\mathrm{H}+\mathrm{H}+\mathrm{M}^{\mathrm{b}}$ & $2.2 \times 10^{9}$ & 0.5 & $3.877 \times 10^{8}$ \\
\hline $\mathrm{H}_{2}+\mathrm{O}_{2}=\mathrm{OH}+\mathrm{OH}$ & $1.7 \times 10^{8}$ & 0.0 & $2.0 \times 10^{8}$ \\
\hline $\mathrm{H}+\mathrm{O}_{2}+\mathrm{M}=\mathrm{HO}_{2}+\mathrm{M}^{\mathrm{c}}$ & $2.1 \times 10^{12}$ & -1.0 & 0.0 \\
\hline $\mathrm{H}+\mathrm{O}_{2}+\mathrm{O}_{2}=\mathrm{HO}_{2}+\mathrm{O}_{2}$ & $6.7 \times 10^{13}$ & -1.42 & 0.0 \\
\hline $\mathrm{H}+\mathrm{O}_{2}+\mathrm{N}_{2}=\mathrm{HO}_{2}+\mathrm{N}_{2}$ & $6.7 \times 10^{13}$ & -1.42 & 0.0 \\
\hline $\mathrm{HO}_{2}+\mathrm{H}=\mathrm{H}_{2}+\mathrm{O}_{2}$ & $2.5 \times 10^{10}$ & 0.0 & $2.9 \times 10^{6}$ \\
\hline $\mathrm{HO}_{2}+\mathrm{H}=\mathrm{OH}+\mathrm{OH}$ & $2.5 \times 10^{11}$ & 0.0 & $7.9 \times 10^{6}$ \\
\hline $\mathrm{HO}_{2}+\mathrm{O}=\mathrm{OH}+\mathrm{O}_{2}$ & $4.8 \times 10^{10}$ & 0.0 & $4.2 \times 10^{6}$ \\
\hline $\mathrm{HO} 2+\mathrm{OH}=\mathrm{H} 2 \mathrm{O}+\mathrm{O}_{2}$ & $5.0 \times 10^{10}$ & 0.0 & $4.2 \times 10^{6}$ \\
\hline $\mathrm{HO}_{2}+\mathrm{HO}_{2}=\mathrm{H}_{2} \mathrm{O}_{2}+\mathrm{O}_{2}$ & $2.0 \times 10^{10}$ & 0.0 & 0.0 \\
\hline $\mathrm{H}_{2} \mathrm{O}_{2}+\mathrm{M}=\mathrm{OH}+\mathrm{OH}+\mathrm{M}$ & $1.3 \times 10^{14}$ & 0.0 & $1.905 \times 10^{8}$ \\
\hline $\mathrm{H}_{2} \mathrm{O}_{2}+\mathrm{H}=\mathrm{HO}_{2}+\mathrm{H}_{2}$ & $1.7 \times 10^{9}$ & 0.0 & $1.57 \times 10^{7}$ \\
\hline $\mathrm{H}_{2} \mathrm{O}_{2}+\mathrm{OH}=\mathrm{H}_{2} \mathrm{O}+\mathrm{HO}_{2}$ & $1.0 \times 10^{10}$ & 0.0 & $7.5 \times 10^{6}$ \\
\hline \multicolumn{4}{|c|}{ 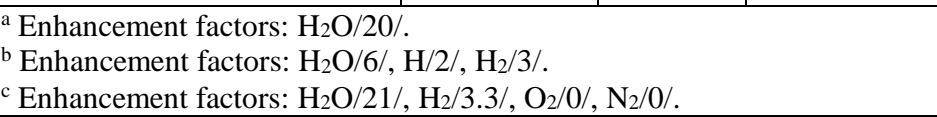 } \\
\hline
\end{tabular}

Table 3 Boundary conditions

\begin{tabular}{|c|c|c|}
\hline Boundary & Parameters & Values \\
\hline \multirow{5}{*}{ Inlet } & Velocity inlet & $5 \mathrm{~m} / \mathrm{s}$ \\
\hline & Gage pressure & $0 \mathrm{~Pa}$ \\
\hline & Turbulent intensity & $5 \%$ \\
\hline & The hydraulic diameter & Regard to inlet diameter \\
\hline & Temperature & $300 \mathrm{~K}$ \\
\hline \multirow{3}{*}{ Outlet } & Gage outlet pressure & $0 \mathrm{~Pa}$ \\
\hline & Turbulent intensity & $5 \%$ \\
\hline & The hydraulic diameter & Regard to outlet diameter \\
\hline \multirow{3}{*}{ Inner wall } & $\begin{array}{c}\text { Interface } \\
\text { No-slip }\end{array}$ & zero-flux for all species \\
\hline & Thermal condition & coupled \\
\hline & Material & steel \\
\hline \multirow{3}{*}{ Out wall } & Radiation and convection & Mixed \\
\hline & Heat transfer coefficient & $15 \mathrm{~W} / \mathrm{m}^{2} \mathrm{~K}$ \\
\hline & Emissivity & 0.7 \\
\hline
\end{tabular}

combustor for MTPV systems is defined as:

$\eta_{\mathrm{tot}}=\eta_{\mathrm{TPV}} \cdot \eta_{\mathrm{Rad}}$

where $\eta_{T P V}$ is MTPV systems efficiency that is assumed to be $15.4 \%$ (Xue et al. (2005)).

Two parameters to measure the nonuniformity coefficient of outer wall temperature $\left(\mathrm{R}_{\mathrm{T}}\right)$ and mean outer wall temperature $\left(T_{m}\right)$ are defined as below (Ansari et al. (2018)):

$\mathrm{R}_{\mathrm{T}}=\left(\frac{\sum_{i=1}^{n}\left[\left[T_{i}-T_{m} \mid A_{i}\right]\right.}{T_{m} \sum_{i=1}^{n} A_{i}}\right) \times 100$ 


$$
\mathrm{T}_{\mathrm{m}}=\frac{\sum_{i=1}^{n} T_{i} A_{i}}{\sum_{i=1}^{n} A_{i}}
$$

\subsection{Numerical Setup}

For the numerical simulation, the Ansys Fluent 17 has been used to solve the governing equations. The coupled algorithm is applied for the velocity pressure decoupling of the Navier-Stokes equations (Jiang et al. 2015). The standard k- $\varepsilon$ model (Kuo et al. (2007)) is used for turbulent flow and the eddy dissipation concept (EDC) model (Akhtar et al. (2015)) are applied for the chemical reaction. 9 species and 19 reversible reaction mechanisms of $\mathrm{H}_{2} /$ air are given in Table 2 (Yang et al. (2014)). The specific heat and the density of the premixed hydrogen-air mixture are computed by incompressible ideal gas law and mixing law, respectively. Viscosity and gas thermal conductivities of the mixture are computed by the weighted mass fraction of all species, and the specific heat of each species is computed utilizing a sectioned polynomial method (Tang et al. (2015a, b)), kinetic theory is used to calculate the mass diffusivity of the $\mathrm{H}_{2} /$ air mixture. The convergence criterion of continuity, momentum, and species equations are $1 \times 10^{-4}$, and lower than $1 \times 10^{-6}$ for the energy equation.

Besides, the boundary conditions in the current work are shown in Table 3.

\subsection{Grid Independency}

In order to determine the minimum number of grid cells to guarantee that the present numerical simulation is independent of the grid cells, moreover, to reduce the computational time, the grid sensitivity is tested (Fig. 3). Three meshes (517610, 759278, and 913851) are used to study the wall temperature profile of combustor $\mathrm{C}$, where premixed hydrogen-air velocity is kept at $5 \mathrm{~m} / \mathrm{s}$. As presented in Fig. 4, the difference in the wall temperature distribution on the three meshes is very small and over 913851 elements, the wall temperature wasn't changed. So, the mesh structure about 913851 cells is used for an accurate simulation.

\subsection{Validation of the numerical simulation}

To validate the numerical simulation of this study, the temperature distribution of the micro-combustor wall is compared with the experimental data reported by Wenming et al. (2015) and with our previous work (Nadimi et al. (2019)). As presented in Fig. 5, in this work, we used dimensionless length, which is defined as $\mathrm{z}$ axial per the total length of the micro-combustor $(\mathrm{z} / \mathrm{L})$. We considered wall temperature of the micro combustor $\mathrm{C}$ where $\mathrm{H}_{2} /$ air equivalence ratio and the inlet velocity are 1 and $5 \mathrm{~m} / \mathrm{s}$, respectively. As shown in this figure, there is a discrepancy at first between experimental results and numerical simulation. However, the maximum difference in the two temperature profiles is $6 \%$ at the beginning of the micro combustor. But this difference is reduced throughout the length of the micro combustor. This error is due to the rectangular cross-section for the micro combustor in experimental results. But in this research, the circular cross-section has been used. Akhtar et al. (2015) discussed the reasons for this difference. However, this simulation is in good agreement with our previous work.

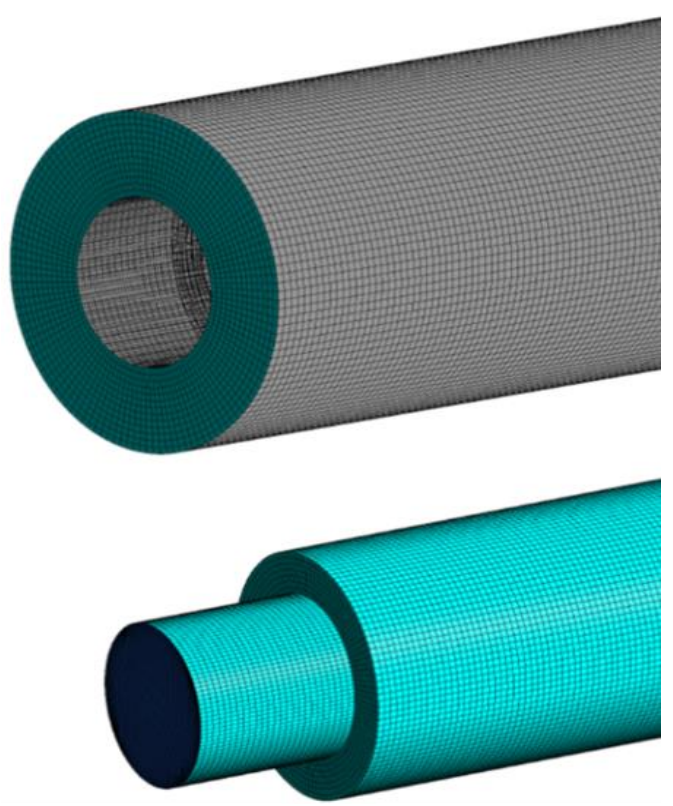

Fig. 3. The computational grid for solid and reaction zones.

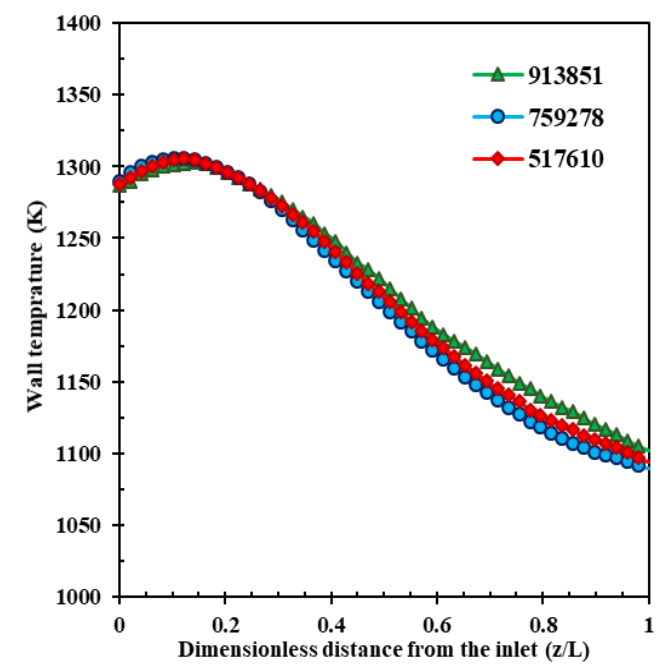

Fig. 4. Mesh independence study for combustor C.

\section{RESUlts AND Discussions}

\subsection{Effects of Micro Combustor Size on Entropy}


Figure 6 presents the entropy generation under various micro combustor size. It can be observed that the variety of micro combustor sizes have essential effects on the entropy generation. By increasing the size of the micro-combustor, the mass flow rate of the inlet increases. It causes an increase in the total entropy generation rate. Figure 7 shows the specific entropy distribution for three micro combustors. It is observed in Fig. 7 that the specific entropy of the smallest micro combustor is lower than that of the largest micro combustor under the same condition. The high entropy areas of them are located in the central region of the micro combustors (contour lines 20,19, and 18). These high entropy areas are gotten smaller by decreasing the size of micro combustors. The micro combustor F causes a lower specific entropy region, that is the major reason why the total entropy generation of the smallest micro combustor is lower than that of others.

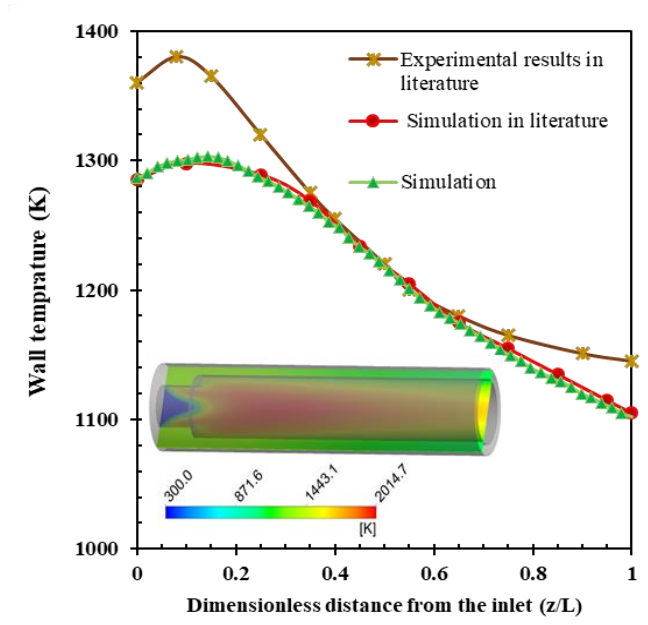

Fig. 5. Validation of the numerical results with experimental data and numerical simulation in literature.

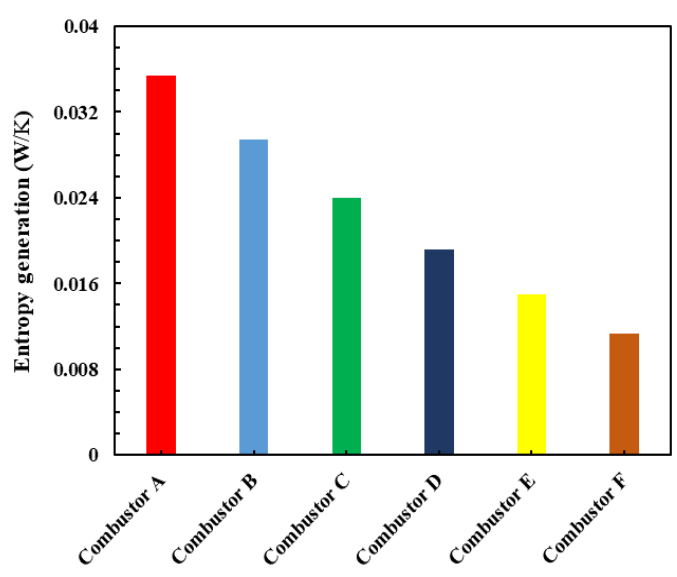

Fig. 6. Entropy generation rate under different micro combustors.

To determine the relationship between the size of the micro combustors and entropy generation rate, we need to normalize the rate of entropy generation and the volume of the micro combustors. To do this, we use the volume and entropy generation rate of micro combustor $\mathrm{C}, \quad \mathrm{S}_{\mathrm{Dim}}=\dot{\mathrm{S}}_{\mathrm{gen}} / \dot{\mathrm{S}}_{\mathrm{gen}}{ }_{C}$, $\mathrm{V}_{\text {Dim }}=\mathrm{V} / \mathrm{V}_{C}$. As it is observed in Fig. 8 with the increasing value of the dimensionless volume, the dimensionless entropy generation rate is increasing due to the high mass flow rate.

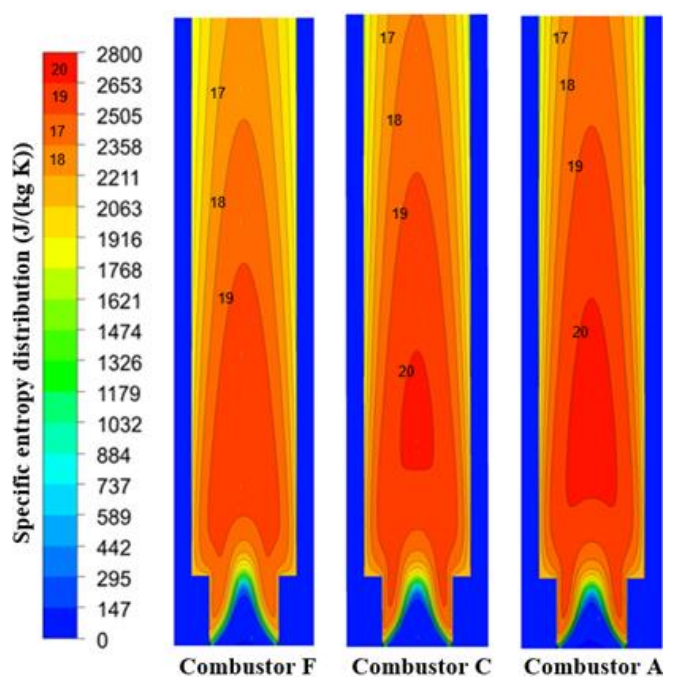

Fig. 7. Effects of micro combustor sizes on specific entropy of premixed hydrogen-air.

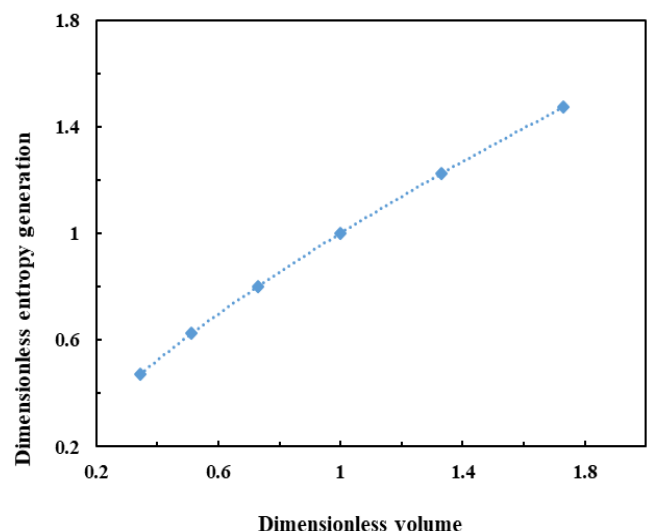

Fig. 8. Dimensionless entropy generation under dimensionless volume.

\subsection{Effects of Micro Combustor Size on Radiation}

Figure 9(a) depicts the radiation power and radiation power efficiency of the micro combustors at a different size. Radiation power has an inverse correlate with micro combustor size. The highest radiation power is obtained by the biggest micro combustor. So, the micro combustor A has a maximum radiation power, and micro combustor $\mathrm{F}$ has a minimum. While micro combustor $F$ has a high mean wall temperature. That's due to the radiation power, according to Eq. 13 has a direct relationship with the out wall surface area. Based on Eq. 15 , the radiation power efficiency has defined the ratio of the radiation power through the micro- 
combustor wall to the total energy input. Therefore, with the increase in the size of the combustor, the total input energy increased, so radiation power efficiency reduces, as shown in Fig. 9(b). The micro combustor $\mathrm{F}$ has a maximum radiation power efficiency, whereas this only 0.04 percent point is higher than micro combustor $\mathrm{E}$. The difference between micro combustor $\mathrm{A}$ and $\mathrm{B}$ is 1.52 percent point. The difference between the largest and smallest micro combustor radiation power efficiency $(\mathrm{A}, \mathrm{F})$ is only a 3.66 percent point. While the radiation power is decreased almost three times from $64.45 \mathrm{~W}$ to $21.83 \mathrm{~W}$. This radiation power can generate $4.1 \mathrm{~W}$ to $1.5 \mathrm{~W}$ of electricity. This means that radiation power efficiency does not change more compared with the radiation power by decreasing the size of the micro combustor smaller.

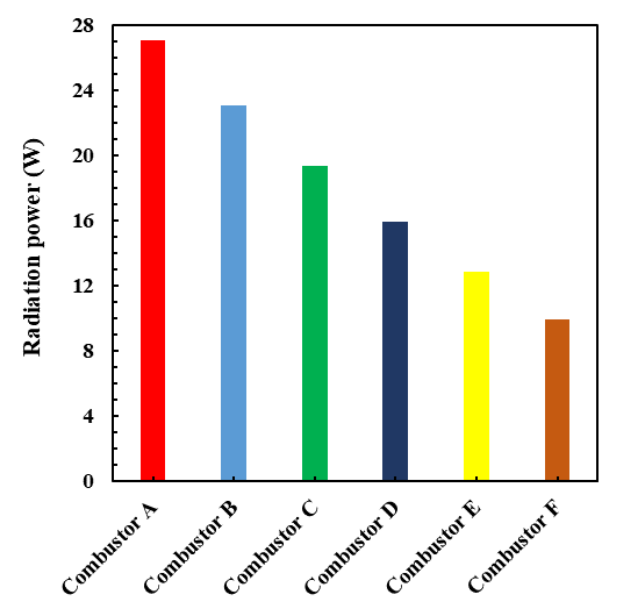

(a)

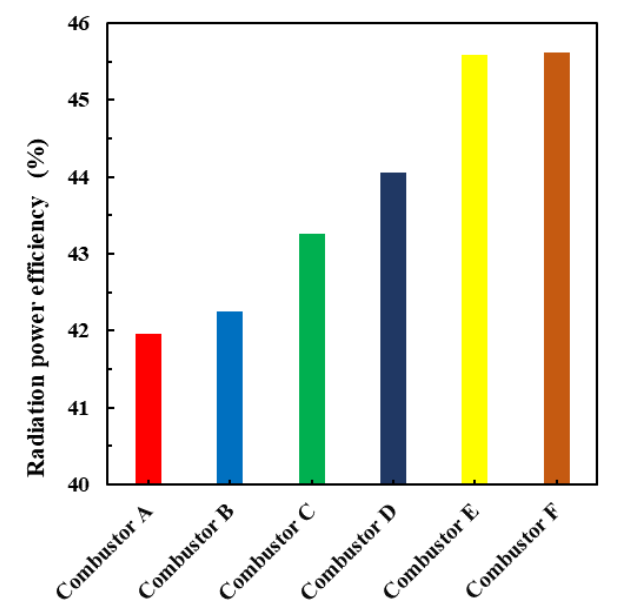

(b)

Fig. 9. (a) Radiation power rate and (b) radiation power efficiency under different micro combustors.

\subsection{Effects of Micro Combustor Size on Temperature}

In order to investigate the effects of micro combustor size on the temperature field, the mean outer wall temperature, nonuniformity coefficient, and contour of temperature at outlet regions are presented in Fig. 10 and Fig. 11, respectively. As shown in Fig. 10 by decreasing the micro combustor size, the mean wall temperature faces an increase from $1195.7 \mathrm{~K}$ to $1221.6 \mathrm{~K}$, and the non-uniformity coefficient is decreasing from 6.04 to 5.29 and the least amount of non-uniformity coefficient indicates more uniform wall temperature. When the dimensions of combustor are reduced by 1.71 times, the mean out wall temperature increased $25.85 \mathrm{~K}$, and the nonuniformity coefficient is decreasing by $12.35 \%$. Figure 11 shows the contours of outlet temperature at different micro combustors. To compare the contours of outlet temperature, we have changed the contours to the same size. For all contours, the outlet temperature climbs up to the peak when moving from an inner wall to a center of the micro combustors. A high-temperature region at the outlet is decreased by making the size of the micro-combustor smaller. The high-temperature distribution at the outlet surface causes that the energy brought away by the outlet gases are increasing.

\subsection{Effects of Micro Combustor size on Exergy Efficiency}

As the size of the micro-combustor reduces, the entropy generation and the temperature of the exhaust gases decrease. Therefore, the exergy loss is diminished, according to Eq. 10, as depicted in Fig. 12(a). The exergy loss is reduced to a considerable level by reducing the micro combustor size. it is decreased from $43.04 \mathrm{~W}$ to $13.39 \mathrm{~W}$ for the largest to the smallest micro combustor.

Based on the above results and Eq. 11, Fig. 12(b) depicts the exergy efficiency for each combustor. The highest exergy efficiency $38.63 \%$ achieved in the combustor $\mathrm{F}$ but, minimum exergy efficiency $33.22 \%$ obtained in the combustor $\mathrm{A}$. When the dimension of the combustor $\mathrm{A}$ is reduced to the combustor F (1.71 times reduction), the exergy efficiency is increased by 5.41 percent point, and the exergy loss is decreased by $68.88 \%$.

To summarize, Table 4 represents various parameters to study the MTPV systems. The signs $\downarrow$ and $\uparrow$ indicate reduce and increase of the parameters. To select the best micro combustor in terms of mean wall temperature $\left(T_{m}\right)$, radiation power efficiency $\left(\eta_{\text {Rad }}\right)$, exergy efficiency $\left(\eta_{\mathrm{II}}\right)$, and total energy conversion efficiency $\left(\eta_{\text {tot }}\right)$. The micro combustor $\mathrm{F}$ has the maximum total energy conversion efficiency $(7.02 \%)$, and it is suitable for MTPV systems.

\section{CONCLUSIONS}

In the present work, a 3D simulation and numerical investigation of the effects of the micro-combustor geometry size gradually reducing on entropy generation, exergy efficiency, and radiation power efficiency have been studied. For this purpose, six micro combustor geometries were constructed 


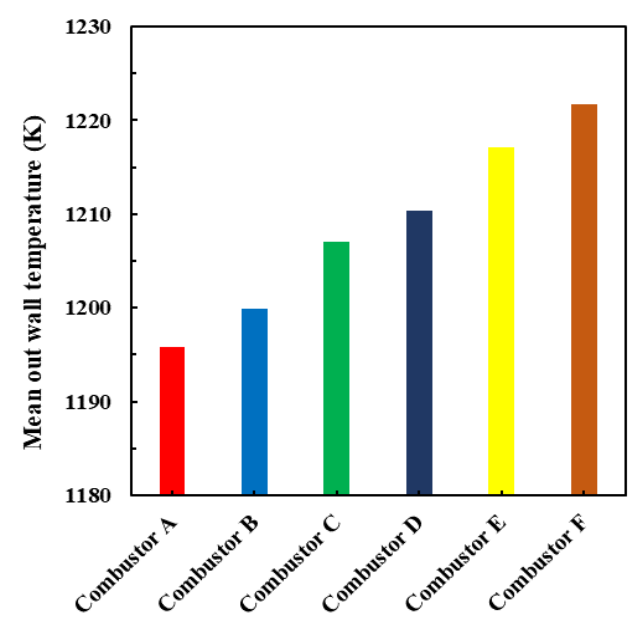

(a)

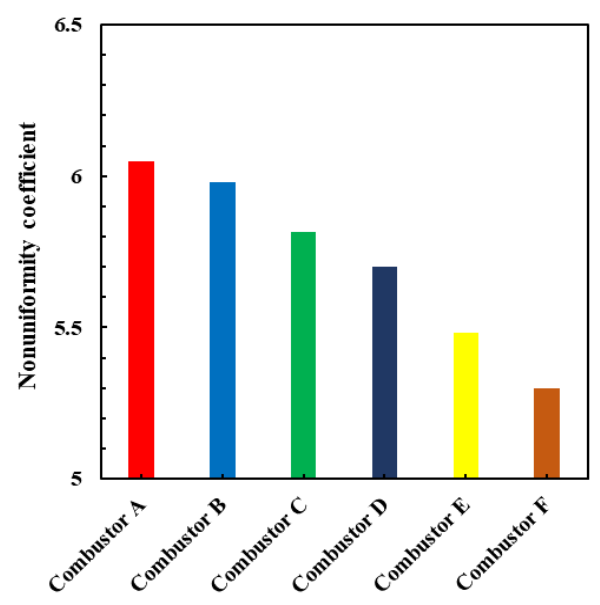

(b)

Fig. 10. (a) Mean out wall temperature and (b) nonuniformity coefficient under different micro combustors.

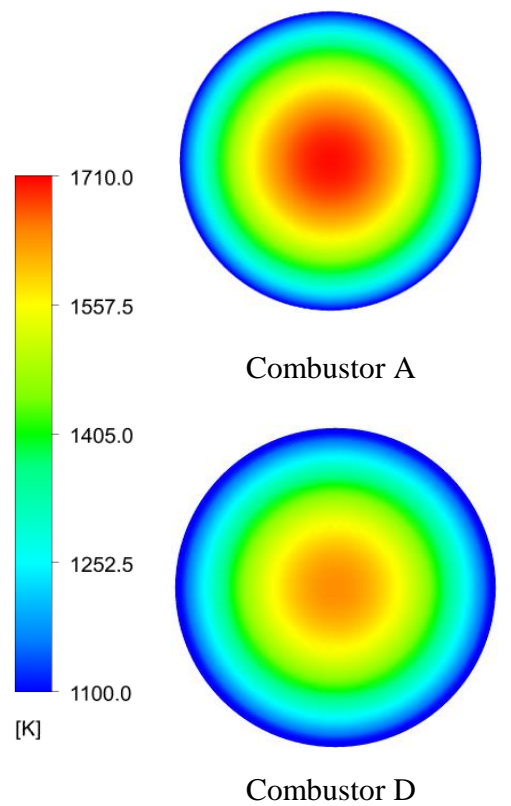

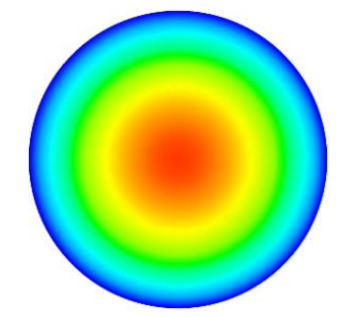

Combustor B

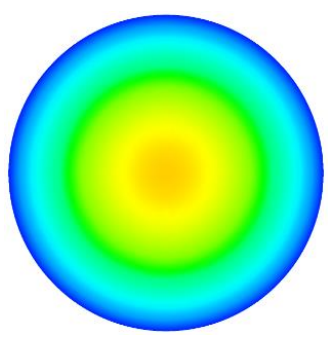

Combustor E

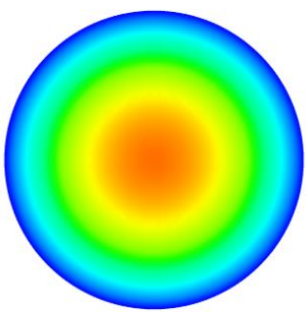

Combustor C

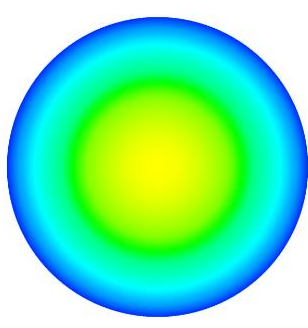

Combustor F

Fig. 11. Contours of outlet temperature for different micro combustors.

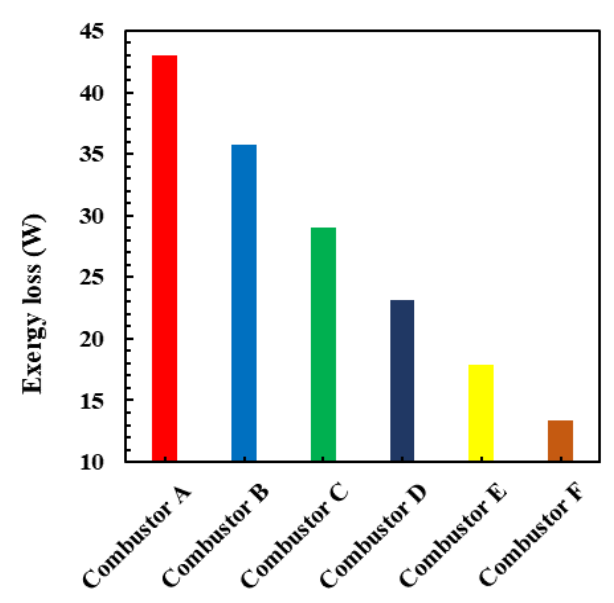

(a)

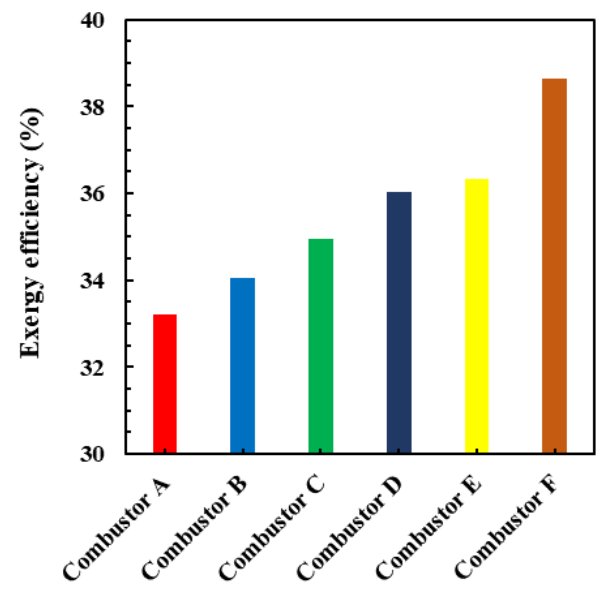

(b)

Fig. 12. (a) Exergy loss and (b) exergy efficiency for different micro combustors. 
E. Nadimi and S. Jafarmadar / JAFM, Vol. 13, No. 4, pp. 1233-1243, 2020.

Table 4 various parameters on the micro combustor performance for MTPV systems. The signs $\downarrow$ and $\uparrow$ indicate the reduction and increase of the parameters

\begin{tabular}{|c|c|c|c|c|c|c|c|c|c|c|}
\hline Parameters & $\dot{Q}_{R}$ & $\dot{Q}_{\text {wall }}$ & $\dot{Q}_{\text {Rad }}$ & $\dot{\mathrm{S}}_{\text {gen }}$ & $\dot{E} x_{\text {loss }}$ & $T_{m}$ & $R_{T}$ & $\eta_{\text {Rad }}$ & $\eta_{\mathrm{II}}$ & $\eta_{\text {tot }}$ \\
\hline Combustor A & $\mathbf{6 4 . 4 5}$ & $\mathbf{3 1 . 4 7}$ & $\mathbf{2 7 . 0 5}$ & $\mathbf{0 . 0 3 5}$ & $\mathbf{4 3 . 0 4}$ & 1195.7 & $\mathbf{6 . 0 4}$ & 41.96 & 33.22 & 6.46 \\
\hline Combustor B & 54.15 & 26.72 & 23.03 & 0.029 & 35.70 & 1199.9 & 5.98 & 42.25 & 34.06 & 6.50 \\
\hline Combustor C & 44.68 & 22.39 & 19.33 & 0.024 & 29.06 & 1207.0 & 5.81 & 43.26 & 34.95 & 6.66 \\
\hline Combustor D & 36.13 & 18.41 & 15.92 & 0.019 & 23.10 & 1210.3 & 5.69 & 44.06 & 36.04 & 6.78 \\
\hline Combustor E & 28.16 & 13.43 & 12.84 & 0.015 & 17.93 & 1217.1 & 5.48 & 45.58 & 36.34 & 7.01 \\
\hline Combustor F & 21.83 & 11.49 & 9.963 & 0.013 & 13.39 & $\mathbf{1 2 2 1 . 6}$ & 5.29 & $\mathbf{4 5 . 6 2}$ & $\mathbf{3 8 . 6 3}$ & $\mathbf{7 . 0 2}$ \\
\hline $\begin{array}{c}\text { Decreasing } \\
\text { combustor size }\end{array}$ & $\downarrow$ & $\downarrow$ & $\downarrow$ & $\downarrow$ & $\downarrow$ & $\uparrow$ & $\downarrow$ & $\uparrow$ & $\uparrow$ & $\uparrow$ \\
\hline
\end{tabular}

under the same boundary conditions for micro TPV systems. The main results of the present work are concluded as follows:

$>$ The micro combustor size has important effects on the temperature, entropy generation, exergy, and radiation of the micro combustors.

$>$ By decreasing micro combustor size, the radiation power decreases but, radiation power efficiency increases. The micro-combustor $\mathrm{F}$ has a maximum radiation power efficiency $45.62 \%$, while it has minimum radiation power $9.96 \mathrm{~W}$.

$>$ The highest mean wall temperature $1221.64 \mathrm{~K}$, and the least nonuniformity coefficient 5.29 obtain at the smallest micro combustor (micro combustor F).

$>$ When the size of the combustor A 1.71 times reduce, exergy loss decreases to $29.64 \mathrm{~W}$, and entropy generation decreases by $68 \%$.

$>$ The highest exergy efficiency $38.63 \%$ achieved in the combustor $\mathrm{F}$ but the minimum exergy efficiency $33.22 \%$ obtained in the combustor A. For the same micro combustor geometry and boundary conditions, by decreasing the micro-combustor geometry size performance of the micro-combustor improved from the perspective of the second law of thermodynamics.

\section{CONFLICT OF INTERESTS}

The authors declare that they have no conflict of interests regarding the publication of this paper.

\section{REFERENCES}

Akhtar, S., J. C. Kurnia and T. Shamim (2015) A three-dimensional computational model of $\mathrm{H}$ 2-air premixed combustion in non-circular micro-channels for a thermo-photovoltaic (TPV) application. Applied Energy 152, 47-57.

Alipoor, A. and M. H. Saidi (2017 Aug). Numerical study of hydrogen-air combustion characteristics in a novel microthermophotovoltaic power generator. Applied Energy 199, 382-399.

Ansari, M. and E. Amani (2018). Micro-combustor performance enhancement using a novel combined baffle-bluff configuration. Chemical Engineering Science 175, 243-56.

Huang, Q., A. Tang, T. Cai, D. Zhao and C. Zhou (2019). Entropy generation analysis of combustion process adopting blended propane/hydrogen fuels in micro-combustor. Chemical Engineering and Processing-Process Intensification 143, 107601.

Jiang, D., W. Yang and J. Teng (2015). Entropy generation analysis of fuel lean premixed $\mathrm{CO} / \mathrm{H} 2 /$ air flames. International Journal of Hydrogen Energy 40 (15), 5210-20.

Jiang, D., W. Yang, K. J. Chua, J. Ouyang and J. H. Teng (2014). Analysis of entropy generation distribution in micro-combustors with baffles. International Journal of Hydrogen Energy 39(15), 8118-25.

Jiaqiang, E., W. Zuo, X. Liu, Q. Peng, Y. Deng and H. Zhu (2016). Effects of inlet pressure on wall temperature and exergy efficiency of the micro-cylindrical combustor with a step. Applied Energy 175, 337-45.

Kuo, C. H. and P. D. Ronney (2007) Numerical modeling of non-adiabatic heat-recirculating combustors. Proceedings of the Combustion Institute 31(2), 3277-84.

Nadimi, E. and S. Jafarmadar (2019). The numerical study of the energy and exergy efficiencies of the micro-combustor by the internal micro-fin for thermophotovoltaic systems. Journal of Cleaner Production 235 , 394-403.

Ni, S., D. Zhao, Y. Sun and E. Jiaqiang (2019). Numerical and entropy studies of hydrogenfuelled micro-combustors with different geometric shaped ribs. International Journal of Hydrogen Energy 44(14),7692-705.

Norton, D. G. and D. G. Vlachos (2004). A CFD study of propane/air microflame stability. Combustion and Flame 138(1-2), 97-107.

Peng, Q., E. Jiaqiang, Z. Zhang, W. Hu, X. Zhao (2018).Investigation on the effects of frontcavity on flame location and thermal performance of a cylindrical micro combustor. Applied Thermal Engineering 130, 541-51. 
E. Nadimi and S. Jafarmadar / JAFM, Vol. 13, No. 4, pp. 1233-1243, 2020.

Sahoo, B. B., U. K. Saha and N. Sahoo (2012) Diagnosing the effects of pilot fuel quality on exergy terms in a biogas run dual fuel diesel engine. International Journal of Exergy 10(1),77-93.

Su, Y., J. Song, J. Chai, Q. Cheng, Z. Luo, C. Lou and P. Fu (2015). Numerical investigation of a novel micro combustor with double-cavity for micro-thermophotovoltaic system. Energy Conversion and Management 106,173-80.

Tang, A., J. Pan, W. Yang, Y. Xu and Z. Hou (2015a). Numerical study of premixed hydrogen/air combustion in a micro planar combustor with parallel separating plates. International Journal of Hydrogen Energy 40(5), 2396-403.

Tang, A., Y. Xu, J. Pan, W. Yang, D. Jiang and Q. $\mathrm{Lu}$ (2015b). Combustion characteristics and performance evaluation of premixed methane/air with hydrogen addition in a microplanar combustor. Chemical engineering science 131,235-42.

Turns, S. R. (2002). An Introduction to combustion: Concepts and Applications. Second Edi. Mc Graw Hill; 200AD.

Wan, J., A. Fan, H. Yao and W. (2015) Flameanchoring mechanisms of a micro cavitycombustor for premixed H2/air flame. Chemical Engineering Journal 275, 17-26.

Wan, J., A. Fan, K. Maruta, H. Yao and W. Liu (2012) Experimental and numerical investigation on combustion characteristics of premixed hydrogen/air flame in a microcombustor with a bluff body. International
Journal of Hydrogen Energy 37(24), 19190-7.

Wenming, Y., J. Dongyue, C. K. Kenny, Z. Dan and P. Jianfeng (2015). Combustion process and entropy generation in a novel microcombustor with a block insert. Chemical Engineering Journal 274, 231-7.

Williams, F. A. (1965) Combustion theory: the fundamental theory of chemical reacting flow systems.

Xue, H., W. Yang, S. K. Chou, C. Shu and Z. Li (2005) Microthermophotovoltaics power system for portable MEMS devices. Microscale thermophysical engineering 9(1), 85-97.

Yang, W. M., K. J. Chua, J. F. Pan and D. Y. Jiang (2014) An H. Development of microthermophotovoltaic power generator with heat recuperation. Energy conversion and management $78,81-7$.

Yang, W. M., S. K. Chou, C. Shu, Z. W. Li and H. Xue (2002) Development of microthermophotovoltaic system. Applied physics letters $81(27), 5255-7$.

Yang, W. M., S. K. Chou, C. Shu, Z. W. Li and H. Xue (2007) Experimental study of microthermophotovoltaic systems with different combustor configurations. Energy conversion and management 48(4), 1238-44.

Zuo, W., E. Jiaqiang, Q. Peng, X. Zhao, Z. Zhang (2017). Numerical investigations on thermal performance of a micro-cylindrical combustor with gradually reduced wall thickness. Applied Thermal Engineering 113,1011-20. 